\title{
Consórcio Doutorado
}

\section{DA REPRESENTAÇÃO AO MONITORAMENTO: A CRIAÇÃO DE UMA ONTOLOGIA DO DISCURSO DE ÓDIO ONLINE BRASILEIRO}

\author{
Luiz Rogério Lopes Silva ${ }^{1}$
}

\begin{abstract}
Resumo: As expressões de discurso de ódio em comunidade online promovem um desserviço a saúde das relações e ampliam a desigualdade social ao reforçarem estereótipos e discriminações. Empresas de Redes Sociais Digitais (RSD), organizações de Direitos Humanos e governos de vários países, inclusive o Brasil, têm encontrado dificuldade em estabelecer ações estratégicas que auxiliem na identificação e contenção do fenômeno. A massa de dados com conteúdo intimidador às minorias historicamente marginalizadas (mulheres, negros, comunidade LGBTI, etc.) provou-se multifacetada e complexa, exigindo um esforço permanente no aperfeiçoamento de tecnologias de identificação e moderação de publicações e comentários em sites como Facebook, Youtube e Twitter. Este estudo consiste na criação de um vocabulário controlado do discurso de ódio online brasileiro, valendo-se das ontologias. O objetivo é propor representação da informação a partir do corpo supervisionado do discurso de ódio no Brasil. O estudo defende a tese que as relações associativas em banco de dados dos RDS quando legitimadas numa ontologia atrelada ao contexto brasileiro e a língua portuguesa corroboram ao conhecimento da problemática do ódio e consequentemente a produção de estratégias mais assertivas à manutenção da tolerância em ambientes online. A ontologia servirá como substrato estratégico na identificação, moderação e combate ao fenômeno por meio de um repositório online colaborativo capaz de analisar e classificar expressões que fomentem o ódio e a violência contra grupos específicos. A metodologia tem perspectiva netnográfica visando uma descrição densa do fenômeno, bem como a organização de categorias de analise submetidas ao escrutínio e a participação cidadã por meio de uma plataforma pública. Espera-se que as análises e ferramentas desenvolvidas pelo trabalho possam contribuir com os estudos de discurso de ódio online e encorajar ações e políticas que minimizem os aspectos nocivos no que tange os ideais democráticos e o respeito à dignidade humana.
\end{abstract}

Palavras-Chave: Discurso de ódio. Ontologia. Plataforma colaborativa. Representação. Monitoramento.

\footnotetext{
1 Doutorando em Gestão da Informação, orientado pelo professor Dr. Rodrigo Eduardo BotelhoFrancisco. Mestre em Comunicação e Política pela Universidade Federal do Paraná. Professor da Escola de Comunicação, Arquitetura e Design no UniBrasil - Centro Universitário (Design e Publicidade e Propaganda). Coordenador da Agência Experimental de Publicidade, Propaganda e Design do Centro Unibrasil. http://lattes.cnpq.br/6377367856927679 E-mail: luizlopescomunicacao@gmail.com
} 


\section{INTRODUÇÃO}

No contexto de ubiquidade da Internet e de um uso massivo das Mídias Sociais $^{2}$, os processos de comunicação e informação estão voltados ao uso social da tecnologia. As pessoas passam a reproduzir comportamentos em novas arenas comunicacionais, circunscrevem e se orientam no exercício de sua cidadania pelos impactos tecnológicos da informação e da comunicação (CASTELLS, 2003,2013). A realidade empresarial, a política e outras esferas da sociedade cruzaram uma era marcada por tecnologia computacional dirigida a processamento específico e temporâneo para outra de tecnologias de informação integradas e ubíquas. Estas mudanças promoveram novos desenhos organizacionais e novos comportamentos, que agora se inserem e desafiam os antigos paradigmas sobre gestão (CASTELLS, 2003).

Neste cenário, as Mídias Sociais se apresentam como ambientes favoráveis para o estudo e aprimoramento de estratégias de gestão nas atividades comerciais, na melhoria de sistemas, segurança e na compreensão de fenômenos sociais (BENEVENUTO et al, 2011). Recuero (2012) defende que as Mídias Sociais são como desveladores de vários aspectos das redes off-line e como complexificadores de seu espaço de atuação. Para ela, as interações são reproduzidas facilmente por outros atores, espalham-se nas redes entre os diversos grupos, migram e tornam-se conversações cada vez mais públicas, moldam e expressam opiniões, geram debates e amplificam ideias (RECUERO, 2012).

Sites como Facebook, Twitter e Youtube, por exemplo, transformaram a natureza dos grupos e as relações de poder, permitindo que os indivíduos se associem e se organizem espontaneamente a partir de interesses comuns, num sistema de flexibilidade estrutural e mediante fluxos de comunicação rápida e constante. A massa de dados produzida nestas plataformas, quando realizada uma leitura apropriada e associação com alguma relevância, pode jogar luz "sobre uma miríade de fenômenos

\footnotetext{
${ }^{2}$ Importante estabelecer a diferença entre Rede Social e Mídias Sociais. Rede Social é "um grupo de pessoas, compreendido através de uma metáfora de estrutura, a estrutura de rede. Os nós da rede representam cada indivíduo e suas conexões, os laços sociais que compõem os grupos. Esses laços são ampliados, complexificados e modificados a cada nova pessoa que conhecemos e interagimos" (RECUERO, 2009, p.29). Já as Mídias Sociais são as dinâmicas de criação de conteúdo, difusão de informação e trocas dentro dos grupos sociais estabelecidos nas plataformas online como sites de rede social, por exemplo (RECUERO, 2012).
} 
sociais incluindo atitudes, intenções, identidade, redes, opiniões, locais e representações" (SLOAN et al, 2016, p. 5), além de permitir uma gestão mais aguçada de organizações públicas e privadas, no intuito de melhorar os fluxos comunicacionais e conter atitudes prejudiciais à saúde das interações e do consumo.

Se por um lado, as Mídias Sociais trouxeram avanços nas dinâmicas de acesso a informação, planejamento estratégico e nos processos comunicacionais, tornaram-se também terreno fértil para observação de aspectos conflituosos da realidade palpável e do relacionamento social, como o ódio e todas as suas manifestações. Bem-David e Matamoros (2016) apontam que os recursos tecnológicos e a lógica corporativa das empresas de RSD interferem na dinâmica das performances de ódio e contribuem para a percepção da retórica do ódio como informação legítima. Para o autor, a lógica do algoritmo não é neutra e pode discriminar de acordo com os interesses da empresa que administra a rede social. $\mathrm{O}$ ódio, portanto, não surge fortuitamente de eventuais discordâncias, mas é também o resultado inevitável do funcionamento das plataformas.

Em 2017, o Twitter declarou em nota a ampliação do que constitui um comportamento odioso em suas comunidades. Na ocasião, a empresa informou que "se as informações de perfil de uma conta incluírem uma ameaça violenta ou múltiplos insultos, epítetos, tropas racistas ou sexistas, incitarem o medo ou reduzirem alguém a menos do que a condição humana, ela será permanentemente suspensa". O Google, empresa proprietária do site YouTube, reconhece em sua política para o discurso de ódio que o trabalho de identificação e remoção de conteúdo odiento não é uma tarefa fácil, exigindo uma compreensão mais ampla entre liberdade de expressão e a dignidade da pessoa: "Há uma linha tênue entre o que é ou não é considerado discurso de ódio. Por exemplo, em geral, não há problemas em criticar uma nação ou estado. No entanto, o conteúdo violará nossa política se o objetivo principal for incitar o ódio contra um grupo de pessoas apenas com base na etnia ou promover a violência ${ }^{3 "}$.

Mark Zuckerberg, presidente do Facebook, reconheceu as limitações do site e se comprometeu de maneira pessoal a encontrar alternativas para o problema do discurso de ódio online: "O mundo se sente ansioso e dividido, e o Facebook tem

\footnotetext{
${ }^{3}$ Política de Discursos de Ódio no Youtube. Disponível em: https://support.google.com/youtube/answer/2801939?hl=pt-BR Acessado em 2 de junho de 2018.
} 
muito trabalho a fazer - seja protegendo a nossa comunidade de abusos e ódio, defendendo a interferência de estados-nação ou assegurando que o tempo gasto no Facebook seja tempo gasto ".' Sheryl Sandberg, diretora de operações da rede social, afirma que "não há espaço para ódio ou violência no Facebook" e reforça que "a rede social usa tecnologia como inteligência artificial para encontrar e remover propaganda terrorista, equipes com especialistas em contraterrorismo e revisores em todo o mundo para manter conteúdos extremistas fora da nossa plataforma",. A representante do Facebook no Brasil, Daniele Fontes ${ }^{6}$, em entrevista a assessoria da Câmara dos Deputados disse que a empresa adotou em 2017 uma ferramenta de proteção a imagens íntimas no Facebook, no Instagram e no Messenger além de ter criado o alerta de conta impostora, onde havendo clonagem de um perfil o dono do perfil original é imediatamente avisado.

Apesar dessas medidas, os sites de redes sociais (SRSs) permitem que pessoas ou grupos continuem alcançando novas audiências, recrutando novos membros e criando comunidades de ódio (BEM-DAVID; MATAMOROSFERNANDEZ, 2016). Numa pesquisa realizada pelo projeto Prism $^{7}$, verificou-se que de um total de 100 relatórios de denúncia para o Facebook, apenas 9 resultaram na remoção dos comentários odiosos. Em entrevista a BBC Brasil ${ }^{8}$, um brasileiro que trabalhou como moderador de discursos de ódio no Facebook afirmou que a rotina de trabalho é estressante, com metas que chegavam até 3.500 monitoramentos diários uma análise a cada oito segundos - e, o espaço físico e a exigência de produção eram muito diferentes dos descontraídos escritórios da empresa no Vale do Silício. Ressaltou que em relação a dinâmica de trabalho, os moderadores só visualizam o nome do autor das publicações e não têm acesso a seus perfis completos; que a missão é apagar, ignorar ou encaminhar a publicação para a avaliação superior - o

\footnotetext{
${ }^{4}$ Facebook muda feed de notícias e desagrada investidores. Disponível em: < https://exame.abril.com.br/mercados/facebook-muda-feed-de-noticias-e-desagrada-investidores/> Acessado em 12 de janeiro de 2018

${ }^{5}$ Conforme <http://tecnologia.ig.com.br/2017-06-23/facebook-discurso-odio.html>. Acessado em 16 de Setembro de 2017.

${ }^{6}$ Debatedoras pedem medidas de proteção as mulheres contra violência na internet. Disponível em: http://www2.camara.leg.br/camaranoticias/radio/materias/RADIOAGENCIA/549973-DEBATEDORASPEDEM-MEDIDAS-DE-PROTECAO-AS-MULHERES-CONTRA-VIOLENCIA-NA-INTERNET.html Acessado em 02 de janeiro de 2018.

${ }^{7} \mathrm{~A}$ banalização do discurso de ódio. Disponível em: $<$ http://www.elperiodico.com/es/sociedad/20160722/estudio-proyecto-prism-denuncia-banalizaciondiscurso-odio-internet-5284591>. Acesso em: 23 de Setembro de 2017.

${ }^{8}$ https://www.bbc.com/portuguese/geral-41912670 Acessado em 03 de Maio de 2018.
} 
que ocorre especialmente em casos de suicídio ou pedofilia, que por sua vez são encaminhados a autoridades. Informou que o texto oficial da plataforma pontua que em casos de "pessoas com visibilidade pública", as chances reais "das ameaças se concretizarem" devem ser levadas em consideração na hora de apagar ou não a postagem. Disse ainda que as decisões, pautadas por políticas internas da rede social, servem para "educar" os algoritmos, que com o tempo repetem as respostas automaticamente, por meio de recursos avançados de identificação de rostos ou frases ofensivas. Com isso, fica evidente que os recursos tecnológicos utilizados na identificação e remoção deste tipo de conteúdo se apresentam insuficientes para conter o fenômeno em comunidades virtuais ${ }^{9}$, exigindo um aprimoramento nos processos de monitoramento e mineração de texto.

Neste contexto, o discurso de ódio online também se configura como um problema de Gestão da Informação, abrangendo não só a tecnologia aplicada a reconhecer as expressões complexas e multifacetadas do fenômeno, mas também na representação desse conhecimento. Trata-se de fazer com que a informação contida nas interações das Mídias Sociais seja processada automaticamente pelos agentes inteligentes mediante o emprego de teorias lógicas ou pelas relações mencionadas em todo o conteúdo destes espaços. Este projeto de pesquisa acredita que uma ontologia ${ }^{10}$ do discurso de ódio em língua portuguesa pode otimizar a implementação computacional, acrescendo uma visão, um recorte, uma projeção do conteúdo odiento. A pretensão não é dar conta dele por inteiro, mas construir colaborativamente um repositório de expressões de nacionalismo extremado, xenofobia, racismo, fundamentalismo religioso, visão reacionária e sentimento de superioridade em relação a minorias historicamente marginalizadas, a fim de promover uma educação à tolerância e a igualdade social.

\section{Questiona-se: Quais representações léxicas do discurso de ódio}

\footnotetext{
${ }^{9}$ Rheingold (1998, tradução nossa) define as comunidades virtuais como "[...] agregações sociais que emergem da rede quando pessoas suficientes promovem discussões públicas por tempo suficiente, com suficiente sentimento humano, para formar redes de relações pessoais no ciberespaço." Roxanne Hiltz (1984) criou o termo Comunidade Online situando essas comunidades mais no reino do trabalho do que do lazer.

${ }_{10}$ Uma ontologia é um conjunto de conceitos padronizados, termos e definições aceitos por uma comunidade particular. Ela inclui a definição desses conceitos, suas propriedades e as restrições entre os mesmos. A mais freqüente definição de ontologia é a de Gruber (GRUBER, T. R., 1993) "uma ontologia é uma especificação de uma conceituação". Seu uso tem sido crescente no âmbito da Web Semântica.
} 
brasileiro podem ser usadas na identificação e moderação do fenômeno em redes sociais digitais?

\section{OBJETIVOS}

O objetivo geral do trabalho é propor representações do discurso de ódio online no Brasil em suas características de cunho racial, LGBTI, sexista, xenofobia, aporofobia, religioso, político-partidário, etário, por aparência e contra pessoas com necessidades especiais físicas e mentais.

\section{Objetivos Específicos}

(a) identificar a estrutura léxica do discurso de ódio presente em comunidades online brasileiras entre os anos de 2018-2020;

(b) construir uma ontologia do fenômeno;

(c) desenvolver um repositório colaborativo online de discurso de ódio online estruturado em sua manifestação explícita e velada.

\section{JUSTIFICATIVA}

As Mídias Sociais não só se tornaram parte integrante da vida cotidiana como também fornecem o potencial para as pessoas experimentarem relacionamentos e comportamentos que reconfiguram o convívio social e exigem cada vez mais atenção de governos e organizações na dinâmica de gestão e manutenção dos direitos fundamentais dos cidadãos.

A proposta da pesquisa aqui apresentada soma esforços com outros estudos e iniciativas no campo interdisciplinar que reconhecem o discurso de ódio como um fenômeno crescente e agravador dos problemas de desigualdade social nas mais diversas frentes (SANTOS,2016). O estudo contribuirá à Representação do Conhecimento. Ao utilizar de uma ontologia na recuperação da informação, a pesquisa oferece subsídios para empresas públicas e privadas na organização de suas políticas gerenciais e na criação de tecnologias da informação com base em processamento de linguagem natural. Neste sentido, ao tornar explícitos axiomas do 
discurso de ódio que restringem modelos, de forma a igualar, tanto quanto possível, os modelos que contém o significado pretendido, o trabalho avança no aprendizado de máquinas e na melhoria dos processos e ferramentas de monitoramento de redes.

A contribuição para a Gestão da Informação está na viabilidade de confrontar o uso das redes sociais online com o alinhamento estratégico do seu uso; está também no aprofundamento dos estudos da natureza social e coletiva do uso da informação, observando os fluxos de interação e o caráter ativo do usuário em sua relação com a informação (ARAÚJO, 2012). Considerando que a organização destas informações desempenha um papel significativo nas tomadas de decisão de empresas de RSD, vale ressaltar que o estudo pode auxiliar na manutenção de política de dados, segurança e privacidade que prometem remover conteúdos de ataque com base em raça, etnia, nacionalidade, religião, orientação sexual, gênero, identidade de gênero e deficiências graves e doenças, contudo, permitem "humor, sátiras ou comentários sociais relacionados a esses tópicos" (FACEBOOK, 2018).

Para a academia, aspectos como a precisão, veracidade, confiança e replicabilidade metodológica poderão ser utilizadas em pesquisas que não necessariamente versam com questões de dignidade da pessoa, mas transitam na identificação de discursos opositores a marcas, patentes, figuras públicas etc. Para o Programa de Pós-Graduação em Gestão da Informação, a contribuição é na melhoria do acervo de estudos sobre mineração de textos, redes sociais, netnografia e comportamento digital. Já no aspecto social, o estudo contribui a formação crítica de sujeitos na Cultura Digital, sinalizando os padrões do discurso de ódio não pelo viés da censura, mas pela educação à tolerância e visando a manutenção dos direitos humanos.

\section{REVISÃO DE LITERATURA}

Além do que já está descrito ao longo do corpo deste projeto, é importante destacar que este trabalho busca na Gestão da Informação (DAVENPORT et al., 2004) um espaço privilegiado para estudo das Mídias Sociais e os fenômenos contemporâneos mediados em novas configurações sociais advindas das propostas e usos das tecnologias no âmbito da Sociedade em Rede (CASTELLS, 2006), em especial nas reflexões de esperança e indignação dos movimentos sociais na era da 
internet (CASTELLS, 2013), bem como a compreensão histórica e epistemológica da configuração de uma Sociedade da Informação (MATTELART, 2002) em seus mais variados desafios (WURMAN, 2005). Busca-se, assim, circunscrever o estudo do discurso de ódio no âmbito da gestão, mediação e uso da informação (VALENTIM, 2010), especialmente a partir das contribuições da representação e análise da informação e do conhecimento.

Em termos do objeto de estudo, colaboram as perspectivas teóricas e conceitos advindos dos estudos de Boyd e Ellison (2007), Recuero ( 2012) e Sloan e Quan-Haase (2017). Em específico, aporta-se as questões do fenômeno de ódio em SRS de Santos (2015) e Matamoros (2016). Já em termos metodológicos seguem-se os estudos netnográficos propostos por Kozinets (2010) numa perspectiva de compreensão das comunidades online (RHEINGOLD, 1998), apoiado por técnicas próprias da Gestão e Ciência da Informação, em especial a mineração de dados (GOLDSCHMIDT; PASSOS, 2005) e análise de conteúdo (NEUENDORF, 2002) que pode ser feita nestes ambientes.

Quanto a ontologia e representação do conhecimento deste estudo, faremos uso das teorias de ontologia e comunicação que permitem interações entre pessoas acerca de determinado conhecimento, pois permitem raciocínio e entendimento sobre um domínio (ALMEIDA; BAX, 2003); formalização - relacionada à especificação da ontologia, que permite eliminar contradições e inconsistências na representação de conhecimento (HOLGATE, 2004; PARREIRAS, 2004); e, representação do conhecimento e reutilização - As ontologias formam um vocabulário de consenso que permite representar conhecimento de um domínio em seu nível mais alto de abstração, possuindo, desta forma, potencial de reutilização (SMITH, 2003).

Naturalmente, outros autores serão agregados no percurso da pesquisa, buscando-se evidenciar um modelo de análise (QUIVY; AMPENHOUDT, 2008) próprio para observação do fenômeno, adequado no âmbito das novas ferramentas de gestão e comunicação propostas pelas Mídias Sociais, bem como o aumento da rigidez na política de controle e cerceamento da prática do discurso de ódio.

\section{PROCEDIMENTOS METODOLÓGICOS}

A proposta metodológica deste trabalho parte da netnografia, numa abordagem mista (qualitativa e quantitativa), com foco interpretativo, adaptado das 
técnicas de pesquisa antropológicas e etnográficas para o estudo das culturas e comunidades online, observando as etapas de pesquisa propostas por Kozinets (2010). Assim, a abordagem netnográfica deste trabalho preza pelo planejamento do estudo, seleção e entrada em campo, coleta de dados, análise e interpretação dos dados, garantia dos padrões éticos e apresentação da pesquisa (KOZINETS, 2010). Eis o detalhamento:

(1) ENTRÉE CULTURAL: uma das principais decisões a serem tomadas pelo pesquisador ao empreender uma pesquisa netnográfica é a seleção da comunidade online que será objeto de estudo (KOZINETS, 2010). Nesta etapa serão definidos o foco e o problema de pesquisa, levando em consideração a escolha de comunidades onlines mais apropriadas aos propósitos do estudo de discurso de ódio entre os anos de 2018-2020. Acontecerá uma observação participativa nos espaços definidos como objetos de estudo, considerando história, cultura, normas, valores e práticas da plataforma e dos usuários. A observação do comportamento da comunidade online verificará características tais como: consciência de tipo de comunidade; rituais e tradições; e responsabilidade moral.

(2) COLETA E ANÁLISE DE DADOS: O monitoramento e a mineração dos dados serão realizados em duas etapas: (a) extração dos dados por meio do API Netvizz e (b) filtragem através de ferramenta desenvolvida por pesquisadores da comunicação que utiliza de palavras-chave/expressões de discurso de ódio, classificando os comentários e postagens em categorias pré-determinadas e escolhidas conforme objetivo de pesquisa. Coleta de dUtilizaremos de Abordagem Baseada em Léxicos e Abordagem de Aprendizagem de Máquinas. A primeira focada em ontologias, usando do software Emotinet, enquanto a segunda aplica algoritmos baseados em características linguísticas (Canales \& Martínez-Barco, 2014) em Processamento de Linguagem Natural.

(3) ÉTICA E APRESENTAÇÃO DA PESQUISA: a pesquisa prevê um protocolo de coleta e análise de dados que respeite o anonimato dos perfis observados dentro das comunidades, respeitando a privacidade dos usuários, para isso, deixará claro para os usuários pesquisados como a coleta de dados foi feita e qual o objetivo deste estudo. A apresentação dos resultados de pesquisa será publicada num repositório colaborativo desenvolvido exclusivamente para tal propósito que objetiva uma construção permanente da ontologia, haja vista que as expressões de ódio são altamente dinâmicas. 


\section{CONSIDERAÇÕES FINAIS}

O discurso de ódio no Facebook é um entreve à saúde das interações e à manutenção dos valores democráticos, da cultura de tolerância, do respeito à dignidade da pessoa e seus direitos fundamentais. A netnografia deste fenômeno em comunidades virtuais além de permitir um conhecimento mais minucioso da dinâmica do discurso odioso, poderá suscitar uma ontologia capaz de auxiliar empresas públicas e privadas nas estratégias para o desenvolvimento de uma cultura de tolerância, além de um aprimoramento dos recursos de mineração e análise de dados.

Ao apresentar a questão de pesquisa, os objetivos, a justificativa e a metodologia desta pesquisa não limitamos os ganhos que o tempo proposto pelo doutorado, a troca de conhecimento entre pesquisadores e a evolução das ferramentas tecnológicas de informação e comunicação poderão acrescentar na conclusão deste trabalho. Dito isso, a pesquisa almeja avançar nas discussões de forma a colaborar com o que já vem sendo desenvolvido na academia e estimular novos desafios nesta seara.

\section{REFERÊNCIAS}

ALMEIDA, M. B.; BAX, M. P. Uma visão geral sobre ontologias: pesquisa sobre definições, tipos, aplicações, métodos de avaliação e de construção. Ci. Inf., Brasília, v. 32, n. 3, p. 7-20, set./dez. 2003.

ARAÚJO, Carlos Alberto Ávila. Paradigma social nos estudos de usuários da informação: abordagem interacionista. Informação \& Sociedade, v. 22, n.1, p. 145159, 2012.

BEN-DAVID, A. e MATAMOROS-FERNANDEZ, A. Hate speech and covert discrimination on social media: Monitoring the Facebook pages of extreme-right political parties in Spain. International Journal of Communication, 10, pp. 11671193. 2016. 
BENEVENUTO, Fabrício; ALMEIDA, Jussara M.; SILVA, Altigran S. Explorando redes sociais online: Da coleta e análise de grandes bases de dados às aplicações. Minicursos do Simpósio Brasileiro de Redes de Computadores (SBRC), 2011.

BOYD, D.; ELLISON, N. Social Network Sites: Definition, history and Scholarship. Journal of Computer-Mediated Communication 13(1):210-230. 2007. http://dx.doi.org/10.1111/j.1083-6101.2007.00393.x.

CASTELLS, Manuel. A galáxia Internet: reflexões sobre a Internet, os negócios e a sociedade. Río de Janeiro: Jorge Zahar Ed., 2003.

CASTELLS, M., \& CARDOSO, G. A Sociedade em Rede - Do Conhecimento à Acção Política, Lisboa: Imprensa Nacional - Casa da Moeda, 2006.

CASTELLS, M. Redes de indignação e esperança: movimentos sociais na era da internet. Tradução de Carlos A. Medeiros. Rio de Janeiro: Zahar, 2013.

DAVENPORT, T.H..; MARCHAND, D. A.; DICKSON, T. Dominando a gestão da informação. Porto Alegre: Bookman, 2004.

FACEBOOK. Disponível em: < https://www.facebook.com/communitystandards/> Acessado em 17 de Maio de 2018.

GOLDSCHMIDT, R. R. ; PASSOS, E. P. L. Data mining: um guia prático conceitos, técnicas, ferramentas, orientações e aplicações. 1. ed. Rio de Janeiro: Editora Campus, 2005.

HOLGATE, L. Creating and using taxonomies to enhance enterprise search. Information Today, Nova Jersey, v. 7, n. 21, p. 10-11, jul./ago. 2004.

KOZINETS, Robert V. Netnografia: a arma secreta dos profissionais de marketing: como o conhecimento das mídias sociais gera inovação. 2010. Disponível em: <http://bravdesign.com.br/wpcontent/uploads/2012/07/netnografia_portugues.pdf>. 
Acesso em: 05 de Outubro de 2017.

MATTELART, A. História da sociedade da informação. São Paulo: Loyola, 2002.

NEUENDORF, K. The content analysis guidebook. Thousand Oaks, California: Sage Publications, 2002.

PARREIRAS, F. S. Introdução à engenharia de ontologias. In: SIMPÓSIO MINEIRO DE SISTEMAS DE INFORMAÇÃO, 1., 2004, Belo Horizonte. Anais... Belo Horizonte: Cotemig, 2004. Disponível em:

$<$ http://www.fernando.parreiras.nom.br/palestras/engeonto.pdf>. Acesso em: $01 \mathrm{de}$ maio 2018.

QUIVY, R., CAMPENHOUT, L. V. Manual de investigação em ciências sociais. $2^{a}$ ed.Lisboa: Gradiva, 2008.

RECUERO, R. Redes Sociais na Internet. Porto Alegre, Sulina, 191 p. 2009.

RECUERO, R. A Conversação em Rede. Porto Alegre, Sulina, 238 p., 2012. RHEINGOLD, Howard. The virtual community. c1998. Disponível em: <http://www.rheingold.com/vc/book/>. Acesso em: 20 de Setembro de 2017.

SANTOS, M. A. M dos. O discurso de ódio em Redes Sociais. Lura Editorial. São Paulo, 176 p., 2016.

SLOAN, L.; QUAN-HAASE, A. The Sage handbook of Social Media. Sage. 2016.

SMITH, B. Ontology. In: FLORIDI, L. Blackwell guide to the philosophy of computing and information. Oxford: Blackwell, 2003. p.155-166.

Disponível em: <http://ontology.buffalo.edu/smith/articles/ontology_pic.pdf>. Acesso em: 15 maio de 2018.

VALENTIM, M. org. Gestão, mediação e uso da informação. São Paulo: Editora UNESP; São Paulo: Cultura Acadêmica, 2010. 390 p. ISBN 978-85-7983-117-1. 
WURMAN, R. S. Ansiedade de informação 2: um guia para quem comunica e da instruções. São Paulo: Editora de Cultura, 2005. 